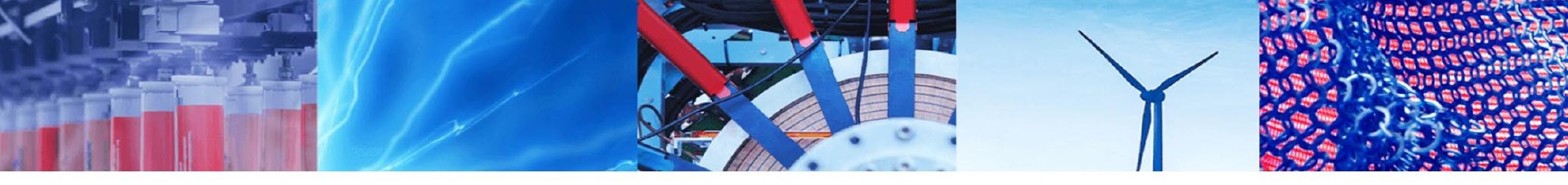

Research Article

\title{
Rescue blankets hamper thermal imaging in search and rescue missions
}

\author{
Markus Isser ${ }^{1} \cdot$ Hannah Kranebitter ${ }^{2} \cdot$ Andreas Kofler $^{3} \cdot$ Gernot Groemer $^{4} \cdot$ Franz J. Wiedermann $^{5}$. \\ Wolfgang Lederer ${ }^{5}$ (i)
}

Received: 3 April 2020 / Accepted: 23 July 2020 / Published online: 9 August 2020

(C) The Author(s) 2020 OPEN

\begin{abstract}
Thermal imaging for unmanned aerial vehicles is used to search for victims in poor visibility conditions. We used a gimbalmounted camera for thermo-radiation measurements of body temperature from persons covered with rescue blankets in the hibernal wilderness setting. Long-wave infrared radiation in the spectral range between 7500 and 13,500 nm was evaluated. Parts of this research have previously been published in a review on electromagnetic radiation reflectivity of rescue blankets (https://www.mdpi.com/2079-6412/10/4/375/htm). Surface temperature measurement was diminished by clothing, namely by $72.6 \%$ for fleece, by $82.2 \%$ for an additional down jacket and by $92.3 \%$ for an additional all-weather jacket, as compared to forehead temperature. Furthermore, we detected that a single-layer rescue blanket is sufficient to render recognition of a body shape impossible. With three layers covering a clothed body infrared transmission was almost completely blocked. However, rescue blankets increase visibility for thermal cameras due to high gradients in temperature. Conspicuously low temperatures from objects of 1 to $2 \mathrm{~m}$ length may indicate reflections from rescue blanket surfaces in a cold environment. Ideally, rescue blankets should be removed from the body to increase the chance of being located when using thermal imaging to search for victims in search and rescue missions.
\end{abstract}

Keywords Emergency medical services $\cdot$ Infrared rays $\cdot$ Insulation $\cdot$ Rescue work $\cdot$ Rescue blanket $\cdot$ Thermography

\section{Introduction}

Rescue blankets are essential components of first aid equipment used by hikers and alpinists in outdoor sports $[1,2]$. Blankets are composite materials and consist of a polyethylene terephthalate sheet coated with a thin aluminium layer with a surface colour of silver or gold on either side [3]. While the polyethylene terephthalate sheet provides high tear resistance [4] and diminishes heat loss from thermo-convection and evaporation, the aluminium layer protects against hypothermia by reflecting infrared (IR) radiation back to the body [5]. Manufacturers recommend turning the silver facing towards the source, e.g. silver side down when aiming to block thermal radiation from the body and silver side up when protection against an external source of heat is desired [6]. As the metallic surface flashes in the sun, it increases a victim's visibility for search and rescue (SAR) services. The silver side of the blanket is highly reflective, but gold up may be more conspicuous in a snow and glacier environment [7]. The use of thermal imaging in unmanned aerial vehicles (UAVs) is increasing in popularity with rescue organizations and fire brigades $[8,9]$. Especially in SAR missions and firefighting, non-contact thermal imaging devices are being deployed more and more. A living person can maintain the core temperature and create thermal gradients between shell

$\triangle$ Wolfgang Lederer, wolfgang.lederer@i-med.ac.at $\mid{ }^{1}$ Medical Division, Austrian Mountain Rescue Service - Tyrol, Telfs, Austria. ${ }^{2} \mathrm{Hall}$ County Hospital, Hall, Austria. ${ }^{3}$ Alpine Police Helicopter Base Tyrol, Innsbruck, Austria. ${ }^{4}$ Austrian Red Cross, Innsbruck, Austria. ${ }^{5}$ Department of Anaesthesiology and Critical Care Medicine, Medical University of Innsbruck, Innsbruck, Austria. 
temperature and ambient air. The detection of victims by thermal cameras is virtually impossible in the absence of thermal gradients or when objects are under water, behind glass or covered by brush-wood [10]. Hypothetically speaking, the detectability of victims by thermal cameras designed for UAVs might also be impaired by diminished IR radiation from rescue blankets.

This experimental study of the sensing of $I R$ radiation was performed with a gimbal-mounted thermal imaging system carried by a balloon. We aimed to explore the capacity of clothing and rescue blankets to block IR transmission in the hibernal wilderness setting.

\section{Methods}

\subsection{Experiment design}

The capacity of fleeces, down jackets and all-weather jackets, gear frequently used by mountain rescue personnel during the winter season, to block IR transmission was assessed [11]. In addition, two different brands of rescue blanket commonly used by ground emergency medical services (EMS) of the Austrian Red Cross (ARC), Mountain Rescue Tyrol (MRT) and EMS helicopter in Austria were investigated [11]. The setting of the investigation was the snow-covered backcountry in the Stubai Valley, Tyrol, Austria. Experiments were conducted after local sunset to exclude direct external solar influx. Parts of this research have previously been published in a review on electromagnetic radiation reflectivity of rescue blankets [11].

Thermal imaging was performed with an IR camera lifted to altitudes of $5 \mathrm{~m}$ and $50 \mathrm{~m}$ above ground with a gas-filled balloon (Search Systems, Craigavon, UK). We chose short distances between the object and the camera to minimize the effects of absorption and refraction by air and by water vapour in order to keep interference from atmospheric conditions low $[11,12]$. Furthermore, the two distances were within the recommended maximum viewing distances for recognition of a target having a length of 1 to $2 \mathrm{~m}$. Temperature and humidity were measured simultaneously (testo, $175 \mathrm{H1}, 79822$ Titisee-Neustadt, Germany). Two test subjects were positioned in supine position on insulating sheets (Salewa, 39100 Bozen, Italy) at a $60^{\circ}$ angle relative to the camera. Body temperature of the two test subjects was measured at the beginning of the experiment from the skin of the forehead using an IR thermometer (ototemp, Exergen Corporation Boston, MA, USA). Investigations were performed in accordance with the rules of the Declaration of Helsinki, revised in 2013 [13]. Despite restricted applicability to experimental studies we applied STROBE statement checklist of items in reporting as applicable [14]. There was no need for human research ethics approval according to the Ethics Committee of the Medical University of Innsbruck as we were testing a licensed medical device within its approved application with healthy volunteers. Written informed consent was obtained from two Austrian Mountain Rescue Service volunteers, who participated in the study under the understanding that results and thermos-photographs would be published in a scientific journal.

\subsection{Thermal imaging by IR camera}

For thermography a radiometric thermal camera (DJI Zenmuse XT, Shenzhen, China) was used to detect longwave IR in the spectral range between 7500 and $13,500 \mathrm{~nm}$ (uncooled microbolometer, image resolution: $640(\mathrm{H}) \times 512$ (V), pixel pitch: $17 \mu \mathrm{m}$, lens model: $13 \mathrm{~mm}$; digital zoom: $8 \times$; sensitivity: $<50 \mathrm{mK}$ at $f / 1.0$; accuracy of $\pm 10^{\circ} \mathrm{C}$; operating temperature: -10 to $40^{\circ} \mathrm{C}$ at a relative humidity between 5 and $95 \%)$. The camera was mounted on a Zenmuse XT gimbal at a controllable range of tilt: +30 to $-90^{\circ}$, pan: $\pm 320^{\circ}$ and roll: $\pm 15^{\circ}$ and was remotely controlled $[11,15]$. To diminish reflection we kept the view angle within $60^{\circ}$ of straight-on and oblique measurements $[11,12]$. The camera was activated and calibrated half an hour prior to measurements to allow adjustment of the thermal imaging device to the low surrounding air temperatures. Measured values were recorded and additionally documented with single-shot images. Radiometric measurements mostly depend on surface emissivity and reflectivity of IR radiation [12]. Emissivity $(E)$ defined as the ability to emit heat via the surface depends on various factors such as surface morphology, viewing angle, material composition and temperature. The emissivity coefficient $(\varepsilon)$ indicates the radiation of heat from different materials. The technical notes specify $\varepsilon=0.90$ for textiles, for anodized aluminium $\varepsilon=0.55$, for snow $\varepsilon=0.83$ and for skin $\varepsilon=0.98$ [12]. Reflectivity $(R)$ is defined as the ability to reflect heat from the surface of materials. $R$ is more relevant at a short distance as both the heat sustained from the surface and the reflected temperature of the background environment influence the measurement. $E$ and $R$ are complementary [12].

\subsection{Potential confounders and effect modifiers}

Remote temperature sensing using a thermal camera relies on the ability to accurately compensate for surface characteristics, atmospheric interference and the imaging system [12]. Differences in surface temperatures are assessed by interpreting the intensity of IR radiation detected by the camera in the central picture section. Image focus, blur and angular resolution influence the measurements [12]. Scene emissivity and background temperature can 
be calibrated to improve the precision of measurements. Imaging systems provide further adjustments with digital detail enhancement, active contrast enhancement and high-gain mode with increased sensitivity to temperature differences [15].

Clothing protects from loss of body temperature and from gain of surrounding heat. In cold climate heat loss occurs when skin temperature exceeds temperature of ambient air. Heat transfer $(P)$ is caused predominantly by radiation (P1) and to some extend by conduction (P2) when ignoring thermo-convection (1) [16].

$P=\mathrm{P} 1+\mathrm{P} 2$

Temperature on the outside cloth surface is expected to be somewhere between skin temperature and ambient temperature depending on textile properties [16].

Thermal radiation (P1) depends on emissivity coefficient $(\varepsilon)$, the Stefan-Boltzmann constant $(\sigma)$, the radiating surface area $(A)$ and the thermal gradient between skin and ambient air (Ts - Ta), respectively (2) [16].

$\mathrm{P} 1=\varepsilon \sigma A\left(\mathrm{Ts}^{4}-\mathrm{Ta}^{4}\right)$

Radiating surface area was determined half of the median body surface area (BSA). BSA was calculated from height and weight using Du Bois formula [17].

We sequentially analysed three different conditions: subject clothed in a fleece (TLT Light Thermal Jacket, Dynafit, 4591, Molln, Austria), with an additional down jacket (Eruption Down Jacket, Dynafit, 4591, Molln, Austria) and with a Gore-Tex jacket (GORE-TEX, W.L.Gore \& Associates, Inc., 91782 Pleinfeld, Germany) worn over the first two pieces of clothing [11]. IR radiation from the body trunk was measured with a thermal camera. The values were related to skin temperature measured at the forehead with an infrared thermometer. Thermal gradients were calculated as the proportion of measured surface temperatures to forehead temperatures (skin) and to external temperatures (air) [11].

Among the variety of available rescue blankets quality of manufacture, thickness and transparency of foils can differ between production series. Two brands of rescue blanket were investigated: ARC Rescue Sheet (ÖRK, A-1230 Vienna, Austria) and MRT Rescue Blanket (LEINA-WERKE GmbH, D-51570 Windeck, Germany) [11]. The polyethylene terephthalate sheets $(160 \times 210 \mathrm{~cm}$ in size, $0.012 \mathrm{~mm}$ in thickness) were $1 \%$ aluminium-coated, with a distinctive surface colour gold on one side and silver on the other side. The blankets of each brand were unpacked and completely unfolded. Sequential measurements were taken in the centre of one, two and three blankets arranged one over the other. Temperature and humidity were monitored for each recording. The values were related to air temperature measured with a negative temperature coefficient thermistor sensor.

The thermal proportions were calculated of measured surface temperatures from rescue blankets on clothed body to measured surface temperatures from rescue blankets on snow. Values were corrected with $\varepsilon$ for aluminium with gold side up [11, 12]. Infrared radiation (IR) was calculated from product of $\varepsilon(0.55), \sigma\left(5.670 \times 10^{-8} \mathrm{~W} \mathrm{~m}^{-2} \mathrm{~K}^{-4}\right)$, the median radiating surface area $(A=1 / 2 \mathrm{BSA})$ and the thermal gradient between surface temperature skin and ambient air (Ts - Ta). Infrared radiation block (IRB) was calculated as percentage of diminished radiation from clothed body covered with one, two and three layers of rescue blankets for aluminium with gold side up (reference value $\operatorname{skin}=100.8 \cdot 10^{-3} \mathrm{~W}$ ).

\subsection{Statistical analysis}

Descriptive statistics were applied using SPSS 25 (IBM SPSS Statistics Standard). Data were presented as medians (measures of central tendency) with ranges (measures of dispersion). As temperature measurements on metallic surfaces indicate reflected apparent temperature, rather than the accurate temperature, we calculated proportions from thermal gradients, e.g. the gradients surface to body temperature and surface to snow temperature under rescue blankets.

Percentage of blocked IR transmission was calculated from measurements of clothed body covered with one, two and three layers of rescue blankets referred to skin temperature.

\section{Results}

Environmental conditions during the investigation were clear sky after local sunset with laminar wind from the west at low speed $\left(<20 \mathrm{~km} \mathrm{~h}^{-1}\right)$. The balloon was east of the object allowing measurements less than $60^{\circ}$ normal to the surface. Atmospheric conditions changed during measurement as relative humidity was increasing due to temperature decline. A total of three samples per brand were tested in eight trials, four with gold side up and four with silver side up. Thermal images of rescue blankets on snow surface exposed with either gold or silver side at $5 \mathrm{~m}$ distance indicated different surface temperatures (Fig. 1).

The thermal gradients between forehead and textile clothing (at median air temperature: $-4.9{ }^{\circ} \mathrm{C}$ and median humidity: $89.3 \%$ ) increased with the number of covering garments, indicating cumulative thermo-protection. As compared to forehead temperature, surface temperature measurement was diminished by $72.6 \%$ for fleece, by $82.2 \%$ for an additional down jacket and by $92.3 \%$ for an 
Fig. 1 Thermal images of model in supine position on an insulating sheet and rescue blankets on snow surface exposed with gold $(\mathrm{g})$ or silver (s) side up at $5 \mathrm{~m}$ distance (air temperature: $-6.2^{\circ} \mathrm{C}$ : snow temperature: $-7.6^{\circ} \mathrm{C}$, respectively, $-6.3^{\circ} \mathrm{C}$ when considering the emissivity coefficient $\varepsilon=0.83$ for snow) [11]

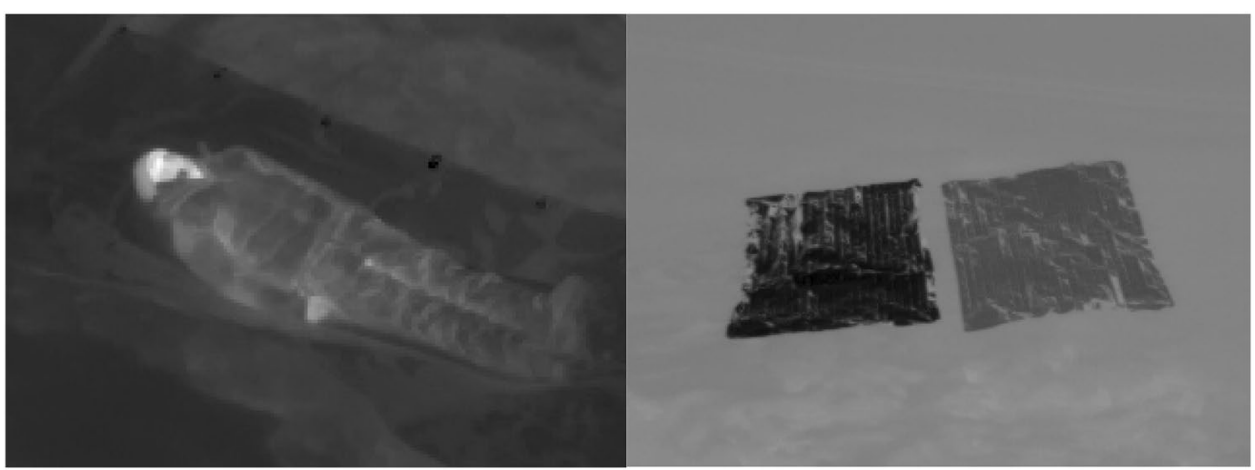

Table 1 Thermo-radiation measurements of body temperature through various types of textile clothing with a thermal camera at distances of $50 \mathrm{~m}$ (median body-air gradient: $38.3^{\circ} \mathrm{C}$ at air temperatures: -1.3 to $-2.5^{\circ} \mathrm{C}$; humidity: 62.3 to $77.1 \%$ ) and $5 \mathrm{~m}$ (body-air gradient: $41.2{ }^{\circ} \mathrm{C}$ at air temperatures: -4.4 to $-5.3{ }^{\circ} \mathrm{C}$; humidity: 87.0 to $91.5 \%)$

\begin{tabular}{|c|c|c|c|c|}
\hline & \multicolumn{2}{|c|}{$50 \mathrm{~m}$ distance } & \multicolumn{2}{|c|}{$5 \mathrm{~m}$ distance } \\
\hline & Temp. & єTemp. & Temp. & $\varepsilon$ Temp. \\
\hline \multicolumn{5}{|c|}{ Thermal gradients (skin-clothing) } \\
\hline Body fleece $\left({ }^{\circ} \mathrm{C}\right)$ & 25.9 & 26.5 & 29.9 & 30.6 \\
\hline Body-down jacket $\left({ }^{\circ} \mathrm{C}\right)$ & 33.3 & 32.1 & 35.5 & 34.3 \\
\hline Body-Gore-Tex $\left({ }^{\circ} \mathrm{C}\right)$ & 33.6 & 33.8 & 38.0 & 37.8 \\
\hline \multicolumn{5}{|c|}{ Thermal proportions (clothing-(skin-air)) } \\
\hline Fleece (\%) & 67.8 & 69.2 & 72.6 & 74.2 \\
\hline Down jacket (\%) & 86.6 & 87.8 & 82.8 & 83.3 \\
\hline Gore-Tex (\%) & 87.7 & 88.6 & 92.3 & 91.9 \\
\hline
\end{tabular}

Thermal gradients (skin-clothing) were calculated between body temperature (skin) and textile clothing surface. Thermal proportions (clothing-(skin-air)) were calculated as the proportion of measured clothing surface temperature and the gradient body (skin) to external temperature (air). Values are expressed as temperature (Temp.) and adjusted values ( $\varepsilon$ Temp.) corrected with the emissivity coefficient $\varepsilon=0.90$ for textiles

additional all-weather jacket worn over the first two garments. Thermo-radiation measurements were comparable between 5 and $50 \mathrm{~m}$ distances (Table 1 ).

Body temperature of participants dressed in fleece, plus a down jacket, plus an all-weather jacket was measured by thermo-radiation from rescue blankets at $5 \mathrm{~m}$ and $50 \mathrm{~m}$ distances and compared to thermo-radiation measurements of a single-layer rescue blanket on snow. Thermal gradients were higher when the gold side was up (Table 2).

It was not possible to recognize the shape of a body when test subjects were covered with one layer of rescue blanket. In median $82.1 \%$ of reduction in measured surface temperatures from single-layer rescue blankets on clothed body compared to measured surface temperatures from rescue blankets on snow was achieved (Table 3 ). With three layers of rescue blankets transmission of IR from clothed body was blocked almost completely referred to skin temperature (Table 3).

\section{Discussion}

In our experimental study we found that rescue blankets can effectively reflect long-wave IR in the spectral band between 7500 and 13,500 $\mathrm{nm}$. Thermal measurements taken in our study confirm that winter clothing provides excellent protection against heat loss $[18,19]$. As the heat radiated by a clothed body is expected to be minimal, the contributing thermo-protective effects of rescue blankets, namely by blocking IR radiation, are limited [20]. However, rescue blankets protect against hypothermia not only by reflecting IR radiation emitted by the body, but they even diminish heat loss from thermo-convection and evaporation [5]. In particular, rescue blankets function as vapour barrier and limit the need for shivering thermogenesis [21]. As transmission can be expected to be low for most materials anyway, the main contributors to thermal emission are both reflectivity and emissivity. Rescue blankets were reported to reflect approximately $80 \%$ of body heat [22]. This corresponds to our findings with long-wave IR radiation blocked by one layer of rescue blanket when the gold side was up. There is still controversy regarding which side of a rescue blanket should go outside. On the one hand, the highly reflective silver side of the blanket reflects visible light better than the golden side. On the other hand, gold may be more conspicuous in a snow and glacier environment [7]. In a recent study we were able to show that transmission of near-IR radiation in the IR/visible radiation boundary region is very low, regardless of whether gold or silver is up [23]. We concluded that it does not matter whether gold or silver is up when rescue blankets are used to protect against hypothermia in wilderness emergencies. Parts of this research have previously been published in a review on electromagnetic radiation reflectivity of rescue blankets [11]. 
Table 2 Thermo-radiation measurements from one, two and three layers of two different rescue blankets (AMR: Austrian Mountain Rescue, ARC: Austrian Red Cross) covering a clothed body dressed in a fleece, plus down jacket, plus all-weather jacket (base) as compared to infrared measurements of a singlelayer rescue blanket on snow made with a thermal camera at distances of $50 \mathrm{~m}$ (air temperature: -1.3 to $-5.3^{\circ} \mathrm{C}$; humidity: 62.3 to $91.5 \%)$ and $5 \mathrm{~m}$ (air temperature: -4.4 to $-5.3^{\circ} \mathrm{C}$; humidity 87.0 to $\left.91.5 \%\right)$

\begin{tabular}{|c|c|c|c|c|c|c|c|c|}
\hline & \multicolumn{4}{|l|}{ Gold } & \multicolumn{4}{|l|}{ Silver } \\
\hline & \multicolumn{2}{|l|}{ AMR } & \multicolumn{2}{|l|}{ ARC } & \multicolumn{2}{|l|}{ AMR } & \multicolumn{2}{|l|}{ ARC } \\
\hline & Temp. & عTemp. & Temp. & $\varepsilon$ Temp. & Temp. & عTemp. & Temp. & عTemp. \\
\hline \multicolumn{9}{|l|}{50 m distance } \\
\hline \multicolumn{9}{|c|}{ Thermal measurements from rescue blanket surfaces } \\
\hline One layer $\left({ }^{\circ} \mathrm{C}\right)$ & -34.5 & -19.0 & -37.4 & -20.6 & -12.0 & -6.6 & -10.9 & -6.0 \\
\hline Two layers $\left({ }^{\circ} \mathrm{C}\right)$ & -32.8 & -18.0 & -35.4 & -19.5 & -12.9 & -7.1 & -14.4 & -7.9 \\
\hline Three layers $\left({ }^{\circ} \mathrm{C}\right)$ & -32.4 & -17.8 & -38.1 & -21.0 & -12.7 & -7.0 & -14.3 & -7.9 \\
\hline Blanket on snow $\left({ }^{\circ} \mathrm{C}\right)$ & -44.4 & -24.4 & -42.9 & -23.6 & -23.4 & -12.9 & -21.9 & -12.0 \\
\hline \multicolumn{9}{|c|}{ Thermal gradients (blanket-snow/clothed body) } \\
\hline Base none $\left({ }^{\circ} \mathrm{C}\right)$ & 47.2 & 27.2 & 45.7 & 26.2 & 26.2 & 15.7 & 24.7 & 14.8 \\
\hline Base-1 layer $\left({ }^{\circ} \mathrm{C}\right)$ & 37.3 & 21.8 & 40.2 & 23.4 & 14.8 & 9.4 & 13.7 & 8.8 \\
\hline Base-2 layers $\left({ }^{\circ} \mathrm{C}\right)$ & 35.6 & 20.8 & 38.2 & 22.3 & 15.7 & 9.9 & 17.2 & 10.7 \\
\hline Base-3 layers $\left({ }^{\circ} \mathrm{C}\right)$ & 35.2 & 20.6 & 40.9 & 23.8 & 15.5 & 9.8 & 17.1 & 10.7 \\
\hline \multicolumn{9}{|l|}{$5 \mathrm{~m}$ distance } \\
\hline \multicolumn{9}{|c|}{ Thermal measurements from rescue blanket surfaces } \\
\hline One layer $\left({ }^{\circ} \mathrm{C}\right)$ & -37.3 & -20.5 & -34.9 & -19.2 & -15.6 & -8.6 & -14.3 & -7.9 \\
\hline Two layers $\left({ }^{\circ} \mathrm{C}\right)$ & -31.9 & -17.6 & -38.0 & -20.9 & -16.9 & -9.3 & -16.8 & -9.2 \\
\hline Three layers $\left({ }^{\circ} \mathrm{C}\right)$ & -44.1 & -24.3 & -46.5 & -25.6 & -21.8 & -12.0 & -20.7 & -11.4 \\
\hline Blanket on snow $\left({ }^{\circ} \mathrm{C}\right)$ & -44.4 & -24.4 & -42.9 & -23.6 & -23.4 & -12.9 & -21.9 & -12.0 \\
\hline \multicolumn{9}{|c|}{ Thermal gradients (blanket-snow/clothed body) } \\
\hline Base none $\left({ }^{\circ} \mathrm{C}\right)$ & 41.9 & 26.9 & 42.1 & 24.4 & 20.9 & 10.4 & 21.1 & 11.8 \\
\hline Base-1 layer $\left({ }^{\circ} \mathrm{C}\right)$ & 34.8 & 23.0 & 34.1 & 20.0 & 13.1 & 6.1 & 13.5 & 7.1 \\
\hline Base-2 layers $\left({ }^{\circ} \mathrm{C}\right)$ & 29.4 & 20.1 & 37.2 & 21.7 & 14.4 & 6.8 & 16.0 & 8.4 \\
\hline Base-3 layers $\left({ }^{\circ} \mathrm{C}\right)$ & 41.6 & 26.8 & 45.7 & 26.4 & 19.3 & 9.5 & 19.9 & 10.6 \\
\hline
\end{tabular}

Thermal gradients (blanket-snow/clothed body) were calculated between rescue blankets and clothed body and between rescue blankets and snow. Values are expressed as temperature (Temp.) and adjusted values ( $\varepsilon$ Temp.) corrected with the emissivity coefficient $\varepsilon=0.55$ for aluminium with gold side up
In our study, actual temperature measurements did not account for the specific emissivity and values were beyond an expected response uniformity of $\pm 10 \%$. We propose that radiation from the clear sky reflected from the metallic surface contributes to the false low values [12]. Considering the fact that the environmental temperature corresponds to the air temperature, we assumed comparable readings for the superficial temperature of the snow corrected by $\varepsilon=0.83$ and the accurate air temperature. Accordingly, temperature measurements through textiles were plausible when corrected by $\varepsilon=0.90$. Rescue blankets have excellent signalling properties for visible light and for IR. In our study, we observed that temperature measurements taken from the rescue blanket surface displayed very low values when the gold side was up. Presumably, the high reflective, low emissive power of the silver side of the blanket goes with lower net radiant flux as compared to gold [24]. However, even when considering $\varepsilon=0.55$ for aluminium, in our study the calculated values for gold up were still strikingly lower than for silver up. Presumably, net fluxes between object and blanket, on the one hand, and between blanket and external air, on the other hand, circulate through transfer zones [25].

\subsection{Interpretations}

In thermo-radiation measurements the actual temperatures measured are of less importance than are the gradients of infrared radiation between objects. Consequently, in a hot environment, e.g. forest fire, the rescue blanket increases visibility for thermal cameras due to high gradients in temperature. This is comparable to high gradients from conspicuously low temperatures measured on rescue blanket surfaces in a cold environment.

In SAR missions with thermal cameras for UAVs the conscious victim can hear the sound of drones as they approach. When the victim realizes there is a search camera, he should take off the rescue blanket as long as UAVs are near $[11,26]$. Detectability can be further increased by moving. Unconscious victims completely enclosed in a rescue blanket are difficult to locate. According to Johnson criteria there are three categories of object determination: 
Table 3 Surface infrared measurements from one, two and three layers of two different rescue blankets (AMR: Austrian Mountain Rescue, ARC: Austrian Red Cross) covering a clothed body dressed in a fleece, plus down jacket, plus all-weather jacket (base) according to surface measurements made with a thermal camera at distances of $50 \mathrm{~m}$ (temperature air: -1.3 to $-5.3^{\circ} \mathrm{C}$; humidity: 62.3 to 91.5\%) and $5 \mathrm{~m}$ (temperature air: -4.4 to $-5.3^{\circ} \mathrm{C}$; humidity 87.0 to $91.5 \%)$

\begin{tabular}{|c|c|c|c|c|}
\hline & Temp. (\%) & عTemp. (\%) & $\operatorname{IR}\left(10^{-3} \mathrm{~W}\right)$ & IRB (\%) \\
\hline \multicolumn{5}{|l|}{$50 \mathrm{~m}$ distance } \\
\hline One layer & 83.5 & 84.3 & 4.8 & 95.2 \\
\hline Two layers & 79.5 & 80.5 & 3.8 & 96.2 \\
\hline Three layers & 82.0 & 82.9 & 4.4 & 95.6 \\
\hline \multicolumn{5}{|l|}{$5 \mathrm{~m}$ distance } \\
\hline One layer & 82.1 & 83.8 & 4.9 & 95.1 \\
\hline Two layers & 79.3 & 81.7 & 4.2 & 95.8 \\
\hline Three layers & 104.2 & 103.8 & 1.2 & 98.8 \\
\hline
\end{tabular}

The thermal proportions were calculated of measured surface temperatures from rescue blankets on clothed body to measured surface temperatures from rescue blankets on snow. Values display percentage differences in median temperature (Temp.) and adjusted values ( $\varepsilon$ Temp) corrected with the emissivity coefficient $\varepsilon=0.55$

Infrared radiation (IR) was calculated from product of emissivity coefficient ( $\varepsilon=0.55$ for aluminium with gold side up), the StefanBoltzmann constant $\left(\sigma=5.670 .10^{-8} \mathrm{~W} \cdot \mathrm{m}^{-2} \cdot \mathrm{K}^{-4}\right)$, the median radiating surface area $\left(A=0.95 \mathrm{~m}^{2}\right)$ and the thermal gradient $(\mathrm{Ts}-\mathrm{Ta})$ between surface temperature from skin and ambient air

Infrared radiation block (IRB) was calculated as percentage of diminished radiation from clothed body covered with one, two and three layers of rescue blankets for aluminium with gold side up (reference value $\operatorname{skin}=100.8 \cdot 10^{-3} \mathrm{~W}$ )

detection (ability to distinguish an object from the background), recognition (ability to classify the object class, e.g. human) and identification (ability to describe the object in details) [27]. In SAR missions rescue blankets restrain recognition of objects, whereas detection of objects is less impaired. We recommend that camera operators should watch for objects of $1 \mathrm{~m}$ to $2 \mathrm{~m}$ lengths with strikingly different temperatures. However, SAR missions with thermal cameras for UAVs do not substitute for helicopter SAR operations with high-end forward-looking infrared (FLIR) cameras of extremely high sensitivity and an accuracy of $\pm 0.2^{\circ} \mathrm{C}[10]$.

\subsection{Limitations}

External validity of our experimental study results is limited by the following reasons.

Our conclusions are based on experimental results of eight test runs involving new, unused survival blankets. We are aware that the accuracy of the results obtained in our study depends on the quality characteristics of the camera used. Thermal imaging with an accuracy $\pm 10^{\circ} \mathrm{C}$ for measurements of temperature affects the estimated accuracy of measured values. The thermal camera in our experiment was designed for SAR operations with UAVs such as quadcopters and balloons. We cannot extrapolate our findings obtained with thermal cameras for UAVs to show the precision of a FLIR camera in the spectral range between 3000 and 15,000 nm, as used for SAR helicopters [10]. The environmental conditions changed during our investigation with the increase in relative humidity due to temperature decline. In addition, the environmental conditions during the course of a day are unknown. As is known, variations in the atmospheric refraction index due to turbulent fluctuations affect the performance of electro-optical and IR systems and sensors. It is critical for the success of field studies such as search and rescue missions that the imaging system be adjusted for variations in the refractive index [20]. Although the distances between thermal camera and objects were within the maximum viewing distance for the target size in order to provide adequate resolution, radiometric measurements taken in our study appeared colder than the actual surface temperatures. Optical properties of coated surfaces with high $\mathrm{R}$ and low $\mathrm{E}$ may render IR measurements difficult [26]. In the experimental setting this problem could be solved by black painting of the surface, but black rescue blankets are not practicable in emergency medicine care. Over and above, sky radiation reflected from the metallic rescue blankets might have influenced the measurements.

As we measured immediately after covering the subject with a rescue blanket, we do not know the accumulating effects from blocking IR radiation, e.g. when thermo-convection occurs within a few minutes from a tight bandage or when condensation is formed on the blanket's interior, the reflective properties of the aluminium foil decline, often within 15-20 min [22]. In addition, we measured IR radiation only from dry surfaces, knowing that moisture may diminish reflection from metallic blankets. Ultimately, there is little information available on the diversity of applications, namely how people use rescue blankets, e.g. placing the blankets over or under the outer layer of clothing. However, we avoided direct skin contact with the rescue foil as the metallic rescue blanket can accelerate heat conduction several times faster than air $[22,26]$.

\section{Summary}

Evaluating the capacity of clothing and rescue blankets to protect against hypothermia and considering limitations by the small experimental setting and scarce information from scientific literature, we realized that rescue blankets can effectively block infrared radiation. 
Parts of this research have previously been published in a review on electromagnetic radiation reflectivity of rescue blankets [11]. Thermo-radiation measurements of body temperature using a gimbal-mounted thermal imaging system revealed that infrared radiation was diminished by clothing, namely by $72.6 \%$ for fleece, by $82.2 \%$ for an additional down jacket and by $92.3 \%$ for an additional allweather jacket, as compared to forehead temperature. Furthermore, we detected that a single-layer rescue blanket is sufficient to render recognition of a body shape impossible. With three layers covering a clothed body infrared transmission was almost completely blocked. However, rescue blankets increase visibility for thermal cameras due to high gradients in temperature. Conspicuously low temperatures from objects of 1 to $2 \mathrm{~m}$ length may indicate reflections from rescue blanket surfaces in a cold environment. Ideally, rescue blankets should be removed from the body to increase the chance of being located when using thermal imaging to search for victims in search and rescue missions.

Acknowledgements Open access funding provided by University of Innsbruck and Medical University of Innsbruck. The authors thank Ralf Lorberg from the Alpine Police Tyrol for operating the thermal camera's remote control. We appreciate the contribution made by Matthias Margesin, RN, and Wolfgang Pinderits of the Austrian Mountain Rescue Service by standing in as the models.

Author contributions M.I. and W.L. helped in conceptualization; A.K.; M.I.; and W.L. helped in methodology; experimental investigation; and data curation; A.K. and M.I. contributed to resources; A.K.; M.I.; G.G.; F.J.W.; and W.L. helped in formal analysis; M.I.; H.K.; F.J.W.; and W.L. wrote the original draft preparation; A.K.; M.I.; H.K.; G.G.; F.J.W.; and W.L. wrote the review and editing; G.G. visualized the study; F.J.W. and W.L. supervised the study; and M.I. and H.K. administrated the project.

Funding Institutional resources were used for running expenses.

\section{Compliance with ethical standards}

Conflict of interest The authors declare no conflict of interests.

Ethics approval Testing a licensed medical device within its approved application with healthy volunteers in a non-invasive experimental study did not require human research ethics approval according to the Ethics Committee of the Medical University of Innsbruck.

Consent to participate Written informed consent was obtained from two models who participated.

Consent for publication All authors gave consent for publication of the paper in a scientific journal.

Open Access This article is licensed under a Creative Commons Attribution 4.0 International License, which permits use, sharing, adaptation, distribution and reproduction in any medium or format, as long as you give appropriate credit to the original author(s) and the source, provide a link to the Creative Commons licence, and indicate if changes were made. The images or other third party material in this article are included in the article's Creative Commons licence, unless indicated otherwise in a credit line to the material. If material is not included in the article's Creative Commons licence and your intended use is not permitted by statutory regulation or exceeds the permitted use, you will need to obtain permission directly from the copyright holder. To view a copy of this licence, visit http://creativecommons .org/licenses/by/4.0\%.

\section{References}

1. Zafren K, Giesbrecht GG, Danzl DF, Brugger H, Sagalyn EB, Walpoth B, Weiss EA, Auerbach PS, McIntosh SE, Némethy M, McDevitt M, Dow J, Schoene RB, Rodway GW, Hackett PH, Bennett BL, Grissom CK (2014) Wilderness Medical Society Practice Guidelines for the out-of-hospital evaluation and treatment of accidental hypothermia: 2014 update. Wilderness Environ Med. https://doi.org/10.1016/j.wem.2014.10.010

2. Chadwick S, Gibson A (1997) Hypothermia and the use of space blankets: a literature review. Accid Emerg Nurs. https ://doi.org/10.1016/s0965-2302(97)90001-1

3. Bryan W (2016) The space blanket: your adventure companion. In: The Marshall Star. National Aeronautics and Space Administration. https://www.nasa.gov/centers/marshall/about/star/ star160511.html. Accessed 28 Jan 2020

4. Isser M, Kranebitter H, Fink H, Wiedermann FJ, Lederer W (2020) High tensile strength increases multifunctional use of survival blankets in wilderness emergencies. Wilderness Environ Med 31(2):215-219

5. Ennemoser O, Ambach W, Flora G (1988) Physical assessment of heat insulation rescue foils. Int J Sports Med. https://doi. org/10.1055/s-2007-1025001

6. Rescue blanket gold/silver (2020) https://www.vaude.com/enINT/Products/Made-in-Germany/568/Rescue-blanket-gold/ silver-VPE6. Accessed 22 Jan 2020

7. Professional outdoor survival (202) Which side of an emergency blanket reflects light best? Which side should go up? https://www.pro-outdoorsurvival.com/news/shownews. php?id=14. Accessed 22 Jan 2020

8. Karaca Y, Cicek M, Tatli O, Sahin A, Pasli S, Beser MF, Turedi $S$ (2018) The potential use of unmanned aircraft systems (drones) in mountain search and rescue operations. Am J Emerg Med. https://doi.org/10.1016/j.ajem.2017.09.025

9. Braun J, Gertz SD, Furer A, Bader T, Frenkel H, Chen J, Glassberg E, Nachman D (2019) The promising future of drones in prehospital medical care and its application to battlefield medicine. J Trauma Acute Care Surg. https://doi.org/10.1097/ TA.0000000000002221

10. Infrared training center (2014) Introduction to thermography basics. https://www.flir.com/support-center/training/suas/ webinars/basics-of-suas-and-thermal-imaging/. Accessed 28 Jan 2020

11. Kranebitter $H$, Wallner $B$, Klinger $A$, Isser $M$, Wiedermann FJ, Lederer W (2020) Rescue blankets-transmission and reflectivity of electromagnetic radiation. Coatings. https://www.mdpi. com/2079-6412/10/4/375/pdf

12. FLIR (2020) Drone education lab for thermal applications. https://www.flir.com/suas/delta/. Accessed 12 Feb 2020

13. World Medical Association (2013) Declaration of Helsinki: ethical principles for medical research involving human subjects. JAMA. https://doi.org/10.1001/jama.2013.281053

14. STROBE (2007) Strengthening the reporting of observational studies in epidemiology (STROBE) statement: guidelines for 
reporting observational studies BMJ. https://doi.org/10.1136/ bmj.39335.541782.AD

15. Zenmuse XT (2020) User manual. https://www.dji.com/produ $\mathrm{ct} /$ zenmuse-xt. Accessed 12 Feb 2020

16. Pan $N$ (2019) Unique thermal properties of clothing materials. Global Challenges. 3, 1800082. http/www.global-challengee S.com

17. Du Bois D, Du Bois EF (1916) A formula to estimate the approximate surface area if height and weight be known. Arch Int Med 17(6):863-871

18. Mendenhall MJ, Nunez AS, Martin RK (2015) Human skin detection in the visible and near infrared. Appl Opt. https:// doi.org/10.1364/AO.54.010559

19. Burke M, Dawson C, Allen CS, Brum J, Roberts J, Krekeler MPS (2019) Reflective spectroscopy investigations of clothing items to support law enforcement, search and rescue, and war crime investigations. Forensic Sci Int. https://doi. org/10.1016/j.forsciint.2019.109945

20. Sivaslıgil M, Erol CB, Polat ÖM, Sarı H (2013) Validation of refractive index structure parameter estimation for certain infrared bands. Appl Opt. https://doi.org/10.1364/AO.52.003127

21. Henriksson O, Lundgren PJ, Kuklane K, Holmér I, Giesbrecht GG, Naredi P, Bjornstig U (2015) Protection against cold in prehospital care: wet clothing removal or addition of a vapor barrier. Wilderness Environ Med. https://doi.org/10.1016/j. wem.2014.07.001

22. Renström B (2002) Space or rescue blanket-a bluff? Arctic Med Res 51:212-213

23. Isser M, Kranebitter H, Kühn E, Lederer W (2019) High-energy visible light transparency and ultraviolet ray transmission of metallized rescue sheets. Sci Rep. https://doi.org/10.1038/s4159 8-019-47418-8

24. Viennot L, Décamp N (2014) Which side to put the survival blanket? Analysis and suggestions for activities with students. Published by the MUSE group (More Understanding with Simple Experiments) in the Physics Education Division (PED) of the European Physical Society (EPS) https://cdn.ymaws.com/www. eps.org/resource/collection/016775D4-8888-474D-887F-3E33A EA5E6D0/EPSPED_SurvivalBlanket.pdf. Accessed 30 Mar 2020

25. Burleigh D, Vavilov VP, Pawar SS (2016) The influence of optical properties of paints and coatings on the efficiency of infrared nondestructive testing applied to aluminum aircraft structures. Infrared Phys Technol. https://doi.org/10.1016/j.infra red.2016.06.007

26. Peterson GP, Fletcher LS (1990) Measurement of the thermal contact conductance and thermal conductivity of anodized aluminum coatings. Heat Transf 112:579-585

27. HGH Infrared Systems (2020) Definition of DRI: Detection, Recognition, Identification ranges. https://www.hgh-infrared.com/ FAQ/Perimeter-Security/Definition-of-DRI-Detection-Recognitio n-Identification-ranges. Accessed 11 July 2020

Publisher's Note Springer Nature remains neutral with regard to jurisdictional claims in published maps and institutional affiliations. 